\title{
Treatment options for postmenopausal osteoporosis
}

This article was published in the following Dove Press journal:

Therapeutics and Clinical Risk Management

27 August 2012

Number of times this article has been viewed

\section{Garry M Walsh}

Division of Applied Medicine, School of Medicine and Dentistry, Institute of Medical Sciences, University of Aberdeen, United Kingdom
Correspondence: Garry M Walsh Division of Applied Medicine, School of Medicine and Dentistry, Institute of Medical Sciences, University of Aberdeen, Foresterhill, Aberdeen AB25 2ZD, United Kingdom
To serve our readership better, future editions of Therapeutics and Clinical Risk Management will once again feature the Editor's comments and views on some of the articles published in that issue of the journal.

Bone is a complex tissue that, in addition to protecting vital organs and giving mechanical support for muscles and joints, provides a mineral reservoir essential for calcium homeostasis, together with the microenvironment essential for hematopoiesis. Osteoporosis is the most common metabolic bone disease, with up to a third of postmenopausal women suffering from this increasingly important public health problem. Key characteristics include low bone mineral density with microarchitectural deterioration of bone tissue leading to increased susceptibility to fragility fractures.

Bone remodeling is vital for a healthy skeleton through removal of damaged tissue by the reabsorptive action of osteoclasts, with osteoblasts accounting for generation of new bone matrix. In recent years, our knowledge of the molecular pathways involved in bone formation and resorption has greatly improved, and it is now appreciated that the interplay between osteoclasts and osteoblasts is controlled by a complex array of hormones, cytokines, and growth factors. This has led to the development of new drugs to treat osteoporosis and these have been classified according to their mode of action on this remodeling process. For example, antiresorptive drugs include bisphosphonates and raloxifene, while anabolic drugs such as teriparatide or parathyroid hormone enhance remodelling. ${ }^{1}$

Bone resorption is regulated by a transmembranous and soluble protein highly expressed by osteoclasts known as receptor activator of nuclear factor- $\mathrm{\kappa B}$ (RANK), a member of the tumor necrosis factor receptor superfamily essential for osteoclastogenesis. Denosumab is a fully humanized monoclonal antibody specific for RANK-ligand. Binding of the latter by denosumab prevents its interaction with RANK, thereby leading to a reduction in osteoclast activity and consequently bone resorption. The place of denosumab in the treatment of osteoporosis, particularly in the context of postmenopausal women, has been comprehensively reviewed in the current issue of the journal. ${ }^{2}$ Treatment with denosumab was characterized by rapid, sustained, and reversible reduction in bone turnover markers, a marked increase in bone mineral density at all sites, and a marked decrease in the risk of vertebral, hip, and nonvertebral fractures in women with postmenopausal osteoporosis. The safety and long-term treatment issues associated with denosumab use in osteoporosis was also reviewed by Anastasilakis et $\mathrm{al}^{3}$ in the same issue. These authors point out that although to date the majority of 
studies report that denosumab has a favorable safety profile in large-scale clinical trials, vigilance is required in relation to long-term adverse effects, particularly those related to oversuppression of bone turnover. Other important areas to be considered in osteoporosis include the effect of treatment on bone quality and patient characteristics, compliance, and potential side effects.

Both review articles complement two original papers on postmenopausal osteoporosis and these were from the same group. The first presented an interesting case report of a young woman who was followed up for 5 years after developing vertebral fractures subsequent to pregnancy and lactation. The authors reported that after 5 years of treatment with a daily dose of alfacalcidol $1 \mu \mathrm{g}$, bone mineral density at the patient's lumbar spine (L1, L3, L4) increased by $21.4 \%$, and this was associated with marked reductions in bone turnover markers. ${ }^{4}$ Quantitative ultrasound is a potentially useful noninvasive method for studying bone density and structure in vivo, and quantitative ultrasound parameters, such as speed of sound, may represent a useful tool for measuring responses to treatment for postmenopausal osteoporosis. The bisphosphonate, alendronate, is widely used as a first-line drug for the treatment of postmenopausal osteoporosis, with established efficacy for vertebral, nonvertebral, hip, and wrist fractures. ${ }^{5}$ Therefore, it is of interest that the second original research paper on osteoporosis from this group examined 45 postmenopausal women who had received treatment for more than one year with alendronate. The authors found that treatment resulted in significant decreases in bone turnover markers that were associated with a modest but clinically significant increase in speed of sound at the calcaneus in postmenopausal Japanese women with osteoporosis. ${ }^{6}$ There were limitations to this study which the authors acknowledge, the most important of which is the relatively small sample size and retrospective nature of the study. Therefore, it would be interesting if larger randomized controlled trials were performed to confirm the usefulness or otherwise of speed of sound for measuring responses to treatment for postmenopausal osteoporosis with established and emerging therapies.

\section{Disclosure}

This author reports no conflicts of interest in this work.

\section{References}

1. Mazziotti G, Bilezikian J, Canalis E, Cocchi D, Giustina A. New understanding and treatments for osteoporosis. Endocrine. 2012;41: 58-69.

2. Cavalli L, Brandi ML. Targeted approaches in the treatment of osteoporosis: differential mechanism of action of denosumab and clinical utility. Ther Clin Risk Manag. 2012;8:253-266.

3. Anastasilakis AD, Toulis KA, Polyzos SA, Anastasilakis CD, Makras P. Long-term treatment of osteoporosis: safety and efficacy appraisal of denosumab. Ther Clin Risk Manag. 2012;8:295-306.

4. Iwamoto J, Sato Y, Uzawa M, Matsumoto H. Five-year follow-up of a woman with pregnancy and lactation-associated osteoporosis and vertebral fractures. Ther Clin Risk Manag. 2012;8:195-199.

5. Wells GA, Cranney A, Peterson J, et al. Alendronate for the primary and secondary prevention of osteoporotic fractures in postmenopausal women. Cochrane Database Syst Rev. 2008;1:CD001155.

6. Iwamoto J, Takada T, Sato Y, Matsumoto H. Influence of treatment with alendronate on the speed of sound, an ultrasound parameter, of the calcaneus in postmenopausal Japanese women with osteoporosis: a clinical practice-based observational study. Ther Clin Risk Manag. 2012;8:287-293.
Therapeutics and Clinical Risk Management

\section{Publish your work in this journal}

Therapeutics and Clinical Risk Management is an international, peerreviewed journal of clinical therapeutics and risk management, focusing on concise rapid reporting of clinical studies in all therapeutic areas, outcomes, safety, and programs for the effective, safe, and sustained use of medicines. This journal is indexed on PubMed Central, CAS,

\section{Dovepress}

EMBase, Scopus and the Elsevier Bibliographic databases. The manuscript management system is completely online and includes a very quick and fair peer-review system, which is all easy to use. Visit $\mathrm{http}: / /$ www.dovepress.com/testimonials.php to read real quotes from published authors. 